\title{
Consent for genetic research in a general population: An update on the National Health and Nutrition Examination Survey experience
}

\author{
Geraldine M. McQuillan, $P h D^{1}$, Qiyuan Pan, $P h D^{1}$, and Kathryn S. Porter, $M D^{1}$
}

\begin{abstract}
Purpose: The study determines the consent rates for storage of biologic samples for future research with and without genetic studies and describes trends in sociodemographic factors associated with consent. Methods: We performed an analysis of the characteristics of consenting individuals participating in three data cycles of the National Health and Nutrition Examination Survey, a nationally representative survey of the U.S. population. Results: In the 1999 to 2000 and the 2001 and 2002 surveys, $84.8 \%$ and $90.1 \%$ of eligible participants, respectively, consented to have their biologic samples including DNA stored in a national repository. Female and non-Hispanic black participants were least likely to consent when genetic studies and DNA were included. In the 2003 to 2004 survey, with the discontinuation of the DNA collection, $98.4 \%$ signed the consent document and these race/gender differences were no longer observed. Conclusion: Females and non-Hispanic blacks consistently had lower consent rates during the survey years when genetic studies were mentioned in the consent, but once DNA collection was discontinued these differences disappeared. These findings demonstrate wide acceptance among survey participants for allowing storage of specimens for future studies but indicate the need to explore race/gender issues with the collection and storage of DNA for genetic research. Genet Med 2006:8(6):
\end{abstract} 354-360.

Key Words: informed consent, genetic research, survey, representative sample

The National Health and Nutrition Examination Survey (NHANES), a representative sample of the United States population, randomly selects 5000 individuals each year to participate in the survey. Individuals who agree to participate are interviewed in the home and then are scheduled to be examined in the Mobile Examination Centers (MECs) a few weeks after the home interview. The informed consent document for the examination and the separate consent for the storage of biologic specimens for future use are presented to the participant after the interview in the home is completed. In 2003 we analyzed data from the 1999 and 2000 survey years to describe the sociodemographic predictors of the willingness of NHANES participants to sign the consent and allow their biologic specimens to be used for genetic research. ${ }^{1}$ We now provide an update on the NHANES experience with consent for storage of biologic specimens for future studies during the 4 years of the survey when DNA was collected and the 2 years when it was dropped from the protocol. We also examined the

From the ${ }^{1}$ Division of Health and Nutrition Examination Surveys, National Center for Health Statistics, Centers for Disease Control and Prevention, Hyattsville, Maryland.

Geraldine M. McQuillan, PhD, National Center for Health Statistics 3311 Toledo Road, Room 4204 Hyattsville, MD 20782.

Submitted for publication December 20, 2005.

Accepted for publication March 8, 2006.

DOI: 10.1097/01.gim.0000223552.70393.08 trends among sociodemographic factors associated with consent over time.

\section{METHODS}

\section{Survey design}

NHANES, a series of cross-sectional national surveys conducted since 1971 by the National Center for Health Statistics of the U.S. Centers for Disease Control and Prevention, obtains a nationally representative sample of the U.S. civilian noninstitutionalized population. The surveys use a complex, stratified, multistage probability sample design with unequal probabilities of selection to oversample certain subgroups of people, such as adolescents, African-Americans, and Mexican Americans. ${ }^{2}$ In 1999, NHANES became a continuous survey with 2-year data-release cycles. Persons participating in each survey year are representative of the U.S. population and are examined once in the MECs, with no longitudinal follow-up. Similar procedures were used to select the sample and conduct the interviews and examinations as in previous NHANES surveys. ${ }^{3}$ The surveys provide national statistics on the health and nutritional status of the U.S. population. One of the goals of the survey in the 1999 to 2002 survey was to establish a national probability sample of biologic specimens including genetic material for future research. During the 2003 to 2004 survey years, DNA collection was dropped from the protocol because of funding constraints. 
Data collection for NHANES occurs at three levels: a brief household screening interview, an in-depth household survey interview, and a medical examination in a special MEC. Consent for the examination and a separate consent for the collection of the specimens for future studies were obtained after the individual was selected for participation in the study and the household interview was completed. Only participants aged 20 years or older were eligible for DNA collection in the 1999 to 2002 survey, although biologic samples for future research were collected on all age ranges with either parental or individual consent or assent. Although the consent included the possibility of extracting DNA from saliva, only whole blood was processed for DNA extraction. The NHANES survey and consent documents were approved by the National Center for Health Statistics Research Ethics Review Board.

This article presents the trends in the percentage of participants who signed the "Specimen Storage and Continuing Studies" consent form during the three 2-year cycles of the survey. There were minor changes to the consent document in $2000^{1}$ and a major revision in 2003 and 2004 with the discontinuation of the collection of DNA for future genetic studies. The consent documents used for the storage of biologic specimens in 1999 and 2000 were previously published. ${ }^{1}$ The consent form used in the 2001 to 2002 survey that included DNA collection and future genetic studies and the 2003 to 2004 survey document without this collection are presented in Figures 1 and 2 (online only).

NHANES participants were informed that all the health data collected would be kept strictly private and that the staff were not allowed to discuss their participation in the survey under penalty of Federal law: Sections 308 (d) of the Public Health Service Act (42 USC 242m) and the Privacy Act of 1974 (5USC 552C). Participants who were interviewed and examined, and who agreed to storage of their specimens cannot be identified by any researcher using the NHANES public use microdata files. Data are recategorized, top coded, and/or suppressed before public release if there is any potential for identification of participants.

The purpose of collecting the stored specimens was to provide a resource for new scientific laboratory tests, including genetic tests, that were not available when the participant was examined. Therefore, the participant was informed that no specific studies were currently planned, and that researchers using their samples would not be contacting them for any additional information. They were also told that NCHS would not contact them with specific results but would provide information on the studies being conducted in a newsletter. Proposals for use of their specimens would be reviewed for scientific merit and by an institutional review board to ensure that the proposed research was ethical. Finally, they were told they could remove their specimens at any time and were given a toll-free number to obtain information.

The number of adults aged 20 or more years selected for the survey was 6401 in the 1999 to 2000 survey, 6941 in the 2001 to 2002 survey, and 6971 in the 2003 to 2004 survey. Race/ethnicity based on self-report was categorized as non-
Hispanic white, non-Hispanic black, and Mexican American. Individuals who did not self-select into these categories were classified as "other." Poverty-index was calculated by dividing total family income by the poverty threshold index adjusted for family size at the year of interview. All interviews were conducted in English or Spanish. If another language was spoken by the participant, a family member or local interpreter translated the interview from English. Samples sizes in the poverty index and years of education categories do not equal the total population because of item nonresponse for these variables.

With the addition of a separate consent document for specimen storage and continuing studies including DNA collection in 1999, interviewers expressed some concerns that they needed more training to adequately explain the purpose and potential use of the specimen repository. In 2000 the NHANES program held several training sessions for the interviewers and provided fact sheets and brochures to address the use of the bank and the protections that were in place to ensure that all studies would have adequate technical and ethical review. Interviewers reported that these materials were helpful with answering concerns and in obtaining respondent cooperation.

Participants were able to check a box on the consent form that allowed the storage of blood, urine, or saliva for future studies and sign the form but not agree to have blood or saliva kept for future studies using their genes.

\section{Statistical analysis}

These analyses are based on data used to monitor the survey operations. Rates are therefore not weighted to produce national estimates. Consent rates and $95 \%$ confidence intervals (CIs) and logistic regression analysis were computed using SAS version 9.1 (SAS Institute, Inc. Cary, NC). Differences between subpopulations or survey years were evaluated by examining $P$ values calculated using a univariate $t$ statistic. To correct for multiple comparisons within categories within a survey cycle or between the survey cycles, the Bonferroni correction was applied to this $P$ value. ${ }^{4}$

All variables examined were entered into a logistic regression model to determine which factors independently contributed to an unwillingness to consent in the two study cycles that included the collection of DNA for genetic research. The other racial/ethnic group was deleted from the logistic regression because of the small sample size and the diverse composition of the group, and the language of interview was not modeled because it was not evenly distributed among the three race/ ethnic groups. All other variables were included to control for the effect of age, education, or income on response, and pairwise interactions in the model were explored using a $P=.05$ from the Wald chi-square to test for significance.

\section{RESULTS}

Table 1 presents the overall response rates to the household interview for each of the three data-release cycles (1999-2000, 2001-2002, and 2003-2004) for individuals aged 20 or more 
Table 1

Overall interview response rates for NHANES 1999 to 2004 participants aged 20 or more years by demographic categories

\begin{tabular}{|c|c|c|c|c|c|c|c|c|c|}
\hline \multirow[b]{2}{*}{$\begin{array}{l}\text { Demographic } \\
\text { characteristic }\end{array}$} & \multicolumn{3}{|c|}{$1999-2000$} & \multicolumn{3}{|c|}{ 2001-2002 } & \multicolumn{3}{|c|}{ 2003-2004 } \\
\hline & $\begin{array}{c}\text { Number } \\
\text { eligible }\end{array}$ & $\begin{array}{l}\text { Number } \\
\text { interviewed }\end{array}$ & Percent & $\begin{array}{c}\text { Number } \\
\text { eligible }\end{array}$ & $\begin{array}{l}\text { Number } \\
\text { interviewed }\end{array}$ & Percent & $\begin{array}{r}\text { Number } \\
\text { eligible }\end{array}$ & $\begin{array}{l}\text { Number } \\
\text { interviewed }\end{array}$ & Percent \\
\hline Total & 6401 & 4880 & 76.2 & 6941 & 5411 & 78.0 & 6971 & 5041 & 72.3 \\
\hline \multicolumn{10}{|l|}{ Race/ethnicity } \\
\hline $\begin{array}{c}\text { Non-Hispanic } \\
\text { white (ref) }\end{array}$ & 3047 & 2233 & 73.3 & 3804 & 2878 & 75.7 & 3798 & 2719 & 71.6 \\
\hline $\begin{array}{l}\text { Non-Hispanic } \\
\text { black }\end{array}$ & 1228 & 923 & 75.2 & 1276 & 1026 & $80.4^{a}$ & 1428 & 1008 & 70.6 \\
\hline $\begin{array}{l}\text { Mexican } \\
\text { American }\end{array}$ & 1542 & 1282 & $83.1^{a}$ & 1359 & 1113 & $81.9^{a}$ & 1272 & 985 & $77.4^{a}$ \\
\hline Other & 584 & 442 & 75.7 & 502 & 394 & 78.5 & 473 & 329 & 69.6 \\
\hline \multicolumn{10}{|l|}{ Gender } \\
\hline Male & 3023 & 2269 & 75.1 & 3302 & 2536 & 76.8 & 3375 & 2418 & 71.6 \\
\hline Female (ref) & 3378 & 2611 & 77.3 & 3639 & 2875 & 79.0 & 3596 & 2623 & 72.9 \\
\hline \multicolumn{10}{|l|}{ Age (y) } \\
\hline $20-39$ & 2127 & 1695 & $79.7^{a}$ & 2370 & 19250 & $81.2^{a}$ & 2293 & 1742 & $76.0^{a}$ \\
\hline $40-59$ & 1791 & 1351 & 75.4 & 2075 & 1614 & $77.8^{a}$ & 1918 & 1398 & $72.9^{a}$ \\
\hline $60+($ ref $)$ & 2483 & 1834 & 73.9 & 2496 & 1872 & 75.0 & 2760 & 1901 & 68.9 \\
\hline
\end{tabular}

${ }^{a_{P}}<.05$, comparison within survey years.

Ref $=$ reference for within cycle comparison.

years. Response rates for the interview varied from $72 \%$ to $78 \%$ over the 6 years of the survey included in this report. In most survey years non-Hispanic whites were less likely to agree to be interviewed. There was no significant sex difference in interview consent rates, and in all survey years individuals aged 60 or more years were less likely to participate than younger age groups. Response rates between survey years were significantly higher in the 2001 to 2002 survey compared with the 1999 to 2000 survey, but were significantly lower in the 2003 to 2004 survey when compared with the 2001 to 2002 cycle among the total population and Mexican Americans.

Table 2 presents the percentage of interviewed individuals who signed the "Specimen Storage and Continuing Studies" consent document. There were significant increases in the percentage of participants consenting between the 1999 to 2000 and 2001 to 2002 survey cycles in every demographic group observed except between those aged 50 to 59 years. This significant increase between survey cycles was even more dramatic between the 2001 to 2002 and 2003 to 2004 survey cycles when the mention of DNA collection for genetic studies was removed from the consent document. This significant increase was observed in every demographic category.

In 1999 and 2000, non-Hispanic blacks compared with nonHispanic whites, females, and those with a poverty index less than 1 were significantly less likely to consent to future research, whereas those aged 40 to 59 years were more likely to consent compared with those aged 60 or more years. In 2001 and 2002, females and those living at or above the poverty level were less likely to consent, whereas those with less than a high school education were more likely to consent compared with those with some college education and those aged 40 to 59 years compared with the participants aged 60 or more years. Although participants were given the option of signing the consent form but not checking the box allowing their genes to be used for future studies in the 1999 to 2002 survey, only 43 individuals in 1999 and 2000 and 38 individuals in 2001 and 2002 used this option and signed the form.

The removal of the mention of DNA collection for genetic studies from the consent document in 2003 and 2004 also removed the significant decrease in consent by non-Hispanic blacks and females. In-fact, non-Hispanic blacks and Mexican Americans were significantly more likely than non-Hispanic whites to consent to the storage of specimens.

To determine independent predictors for not consenting to future studies that included genetic research, the 1999 to 2002 data were modeled controlling for age, education, and poverty index (Table 3). Non-Hispanic black race/ethnicity was the strongest predictor for not consenting, followed by female sex. Individuals aged 40 to 59 years were significantly more likely to consent when compared with those age 60 or more years.

\section{DISCUSSION}

NHANES is a national survey that collects biologic samples on a representative sample of the U.S. population. One of the objectives of the survey was to provide a nationally represen- 
Table 2

Consent to future genetic research for NHANES 1999-2002, and nongenetic future research for NHANES 2003-2004 among interviewed participants aged 20 years or more by demographic categories

\begin{tabular}{|c|c|c|c|c|c|c|c|c|c|}
\hline \multirow[b]{3}{*}{$\begin{array}{l}\text { Demographic } \\
\text { characteristic }\end{array}$} & \multicolumn{6}{|c|}{ Future research including genetic studies } & \multirow{2}{*}{\multicolumn{3}{|c|}{$\begin{array}{c}\text { Nongenetic future research } \\
2003-2004\end{array}$}} \\
\hline & \multicolumn{3}{|c|}{$1999-2000$} & \multicolumn{3}{|c|}{$2001-2002$} & & & \\
\hline & $\begin{array}{c}\text { Number } \\
\text { interviewed }\end{array}$ & $\begin{array}{c}\text { Number } \\
\text { consented }\end{array}$ & $\begin{array}{c}\text { Percent } \\
(95 \% \mathrm{CI})^{b}\end{array}$ & $\begin{array}{c}\text { Number } \\
\text { interviewed }\end{array}$ & $\begin{array}{l}\text { Number } \\
\text { consented }\end{array}$ & $\begin{array}{c}\text { Percent } \\
(95 \% \mathrm{CI})^{b}\end{array}$ & $\begin{array}{c}\text { Number } \\
\text { interviewed }\end{array}$ & $\begin{array}{c}\text { Number } \\
\text { consented }\end{array}$ & $\begin{array}{c}\text { Percent } \\
(95 \% \mathrm{CI})^{b}\end{array}$ \\
\hline Total & 4880 & 4136 & $84.8(83.7-85.8)$ & 5411 & 4877 & $90.1(89.3-90.9)$ & 5041 & 4960 & $98.4(98.0-98.7)$ \\
\hline \multicolumn{10}{|l|}{ Race/ethnicity } \\
\hline $\begin{array}{l}\text { Non- } \\
\text { Hispanic } \\
\text { white (ref) }\end{array}$ & 2472 & 2156 & $87.2(85.9-88.5)$ & 2878 & 2593 & $90.1(89.0-91.2)$ & 2719 & 2661 & $97.9(97.3-98.4)$ \\
\hline $\begin{array}{l}\text { Non- } \\
\quad \text { Hispanic } \\
\text { black }\end{array}$ & 942 & 744 & $79.0^{b}(76.4-81.6)$ & 1026 & 904 & $88.1(86.1-90.1)$ & 1008 & 999 & $99.1^{a}(98.5-99.7)$ \\
\hline $\begin{array}{l}\text { Mexican } \\
\text { American }\end{array}$ & 1283 & 1086 & $84.6(82.7-86.6)$ & 1113 & 1026 & $92.2(90.6-93.8)$ & 985 & 978 & $99.3^{a}(98.8-99.8)$ \\
\hline Other & 183 & 150 & $82.0(76.4-87.5)$ & 394 & 354 & $89.8(86.9-92.8)$ & 329 & 322 & $97.9(96.3-99.4)$ \\
\hline \multicolumn{10}{|l|}{ Gender } \\
\hline Male & 2269 & 1968 & $86.7(85.3-88.1)$ & 2536 & 2318 & $91.4(90.3-92.5)$ & 2418 & 2380 & $98.4(97.9-98.9)$ \\
\hline Female & 2611 & 2168 & $83.0^{a}(81.6-84.5)$ & 2875 & 2559 & $89.0^{a}(87.9-90.2)$ & 2623 & 2580 & $98.4(97.9-98.8)$ \\
\hline \multicolumn{10}{|l|}{ Age $(y)$} \\
\hline $20-39$ & 1695 & 1443 & $85.1(83.4-86.8)$ & 1925 & 1741 & $90.4(89.1-91.8)$ & 910 & 902 & $99.1^{a}(98.5-99.7)$ \\
\hline $40-59$ & 1172 & 1172 & $86.8^{a}(84.9-88.6)$ & 1614 & 1478 & $91.6^{a}(90.2-92.9)$ & 832 & 826 & $99.3^{a}(98.7-99.9)$ \\
\hline $60+($ ref $)$ & 1834 & 1521 & $82.9(81.2-84.7)$ & 1872 & 1658 & $88.6(87.1-90.0)$ & 1901 & 1850 & $97.3(96.6-98.0)$ \\
\hline \multicolumn{10}{|l|}{$\begin{array}{l}\text { Language of } \\
\text { interview }\end{array}$} \\
\hline English & 4195 & 3558 & $84.8(83.7-85.9)$ & 4789 & 4302 & $89.9(89.0-90.7)$ & 4548 & 4469 & $98.3(97.9-98.6)$ \\
\hline Spanish & 685 & 578 & $84.4(81.7-87.1)$ & 622 & 575 & $92.4(90.4-94.5)$ & 493 & 491 & $99.6^{a}(99.0-100)$ \\
\hline \multicolumn{10}{|l|}{$\begin{array}{l}\text { Years of } \\
\quad \text { education }^{c}\end{array}$} \\
\hline $\begin{array}{l}\text { Less than } \\
\text { high school }\end{array}$ & 1896 & 1597 & $84.2(82.6-85.9)$ & 1667 & 1527 & $91.6^{a}(90.3-92.9)$ & 1487 & 1466 & $98.6(98.0-99.2)$ \\
\hline $\begin{array}{l}\text { High school } \\
\text { diploma }\end{array}$ & 1097 & 939 & $85.6(83.5-87.7)$ & 1256 & 1150 & $90.9(89.3-92.5)$ & 1269 & 1246 & $98.2(97.5-98.9)$ \\
\hline $\begin{array}{l}\text { Some college } \\
\text { (ref) }\end{array}$ & 1863 & 1588 & $85.2(83.6-86.8)$ & 2458 & 2191 & $89.1(87.9-90.4)$ & 2271 & 2236 & $98.5(98.0-99.0)$ \\
\hline \multicolumn{10}{|l|}{ Poverty index ${ }^{c}$} \\
\hline$<1$ & 850 & 720 & $84.7^{a}(82.3-87.1)$ & 868 & 819 & $94.4(92.8-95.9)$ & 858 & 851 & $99.2(98.6-99.8)$ \\
\hline$\geq 1$ & 3283 & 2890 & $88.0(86.9-89.1)$ & 4107 & 3741 & $91.1^{a}(90.2-92.0)$ & 3866 & 3812 & $98.2(98.2-99.0)$ \\
\hline
\end{tabular}

${ }^{a} P<.05$, comparison within survey years.

${ }^{b} 95 \%$ confidence interval.

'Sample sizes do not add up to total because of item nonresponse.

Ref, reference; CI, confidence interval.

tative specimen bank of biologic specimens, including DNA, for future health studies. High response rates are important to the survey so response bias can be reduced or controlled and estimates generalizable to the U.S. population can be produced.

We first reported differences by demographic groups in acceptance of the "Specimen Storage and Continuing Studies" component of the survey based on response rates in 1999 and 2000. ${ }^{1}$ Participants were told that no results from future testing of their biologic samples would be returned to them and that they could remove their samples at any time. A toll-free number was provided on the consent form so they could call to remove their samples. The NHANES interviewers did not receive comments on not returning future test results, and no 
Table 3

Relative odds for lack of consent to genetic research from logistic regression in adult participants ages 20 years and more, NHANES 1999 to 2002

\section{9-2002}

Demographic

Odds ratio

$(95 \% \mathrm{CI})^{a}$

$P$ value

$\begin{array}{lcc}\text { Race/ethnicity } & & \\ \text { Non-Hispanic black } & 1.7(1.4-2.0) & <.0001 \\ \text { Mexican American } & 1.1(0.9-1.3) & .618 \\ \text { Non-Hispanic white } & \text { Reference group } & \text { Reference group } \\ \text { Sex } & & \\ \text { Female } & 1.3(1.2-1.5) & .0002 \\ \text { Male } & \text { Reference group } & \text { Reference group } \\ \text { Age (y) } & 0.9(0.7-1.0) & .098 \\ 20-39 & 07(0.6-0.9) & .001 \\ 40-59 & \text { Reference group } & \text { Reference group } \\ 60+ & & .154 \\ \text { Education } & 0.9(0.7-1.1) & .171 \\ \text { Some high school } & 0.9(0.7-1.1) & .975 \\ \text { High school graduate } & & \\ \text { Poverty Index } & 1.0(0.8-1.2) & \text { Reference group } \\ <1 & \text { Reference group } & \\ \geq 1 & & \end{array}$

${ }^{a} 95 \%$ confidence interval.

NHANES, National Health and Nutrition Examination Survey; CI, confidence interval.

participant, to date, has ever called to remove his or her samples. Extensive training of our interviewers and the provision of answers to commonly asked questions (Appendix 1) significantly increased this response rate in every demographic category between the two cycles of the survey that contained the collection of DNA for future genetic studies. Training and information did not change the significantly lower response rates for non-Hispanic blacks compared with whites and females compared with males observed in the 1999 to 2000 and 2001 to 2002 surveys. Other studies have demonstrated that minority race/ethnic groups are less willing to participate in genetic research. ${ }^{5,6}$ The consistently lower consent rates for females during the years when consent was sought to store specimens for future genetic studies have not been seen in clinical genetic studies; ${ }^{6,7}$ however, a population-based study in Japan found that female gender and older age were factors for nonparticipation in a population-based cohort study involving genetic research. ${ }^{8}$ Because NHANES participants are selected to be representative of the general U.S. population with no selection if there was any disease or condition, the lack of a personal incentive of a clinically relevant reason to participate in the collection and storage of blood for continuing studies that include genetic studies may impact women more than men when faced with the decision to sign the consent document. A logistic regression analysis to determine independent predictors for not signing the consent document with the genetic research included demonstrated that being non-Hispanic black or female was the independent predictor for not consenting after controlling for age, education, and poverty index.

When the mention of genes and DNA was removed from the Continuing Studies consent document in 2003 and 2004, there was no longer a significant decrease in consent by non-Hispanic blacks and females. Consent also increased from $90.1 \%$ to $98.4 \%$. This change suggests that the concept of genetic research was a cause for concern for some participants in the NHANES survey because removing words directly linking the collection to genetic research significantly increased response rates in every demographic category when the 2003 to 2004 survey was compared with the 2001 to 2002 or 1999 to 2000 surveys when genes were mentioned.

The debate on the appropriate consent for the collection and storage of biologic samples is ongoing and not restricted to only the NHANES project. ${ }^{6,9}$ Because the NHANES is a general health study with no overarching disease or condition driving the data collection, a general consent was requested with the only limitation that the future studies will look at health conditions. This authorization of unlimited future research has been examined in two recent studies with the conclusion that although research participants want to know and consent for the storage of their biologic specimens, the majority of participants studied were not concerned with the particular disease that would be studied. ${ }^{6,9}$ During the two 2-year survey cycles when DNA and genetic studies were included on the consent document, we offered our participants the option of storage of blood, urine, and saliva while not agreeing to the storage of blood to look at genes. Less than $1 \%$ of participants chose to check this box and still sign the consent form. We conclude that we could not properly articulate this option in the consent document; therefore, we plan on a simplified approach to consent for continuing studies in future cycles of the survey that includes the storage of biologic samples to be used for future heath studies including studies using genes.

The results of this current analysis of consent for specimen storage and continuing studies suggest that there is general acceptance across the demographic groups for participation in future research including genetic research in the general U.S. population. As our interviewers, who presented the consent document, gained experience with explaining this component, consent rates improved in every category examined. Although there was a $90 \%$ acceptance of future studies including genetic studies in 2001 and 2002, once the mention of the collection of DNA was removed in the 2003 to 2004 cycle consent form, consent was almost universal with the lowest consent rate in the 60 years or older age group.

The NHANES program is planning to reintroduce the collection of DNA in the 2007 to 2008 survey. The declining cost of DNA preparation has provided an opportunity to include this component in the survey. Because we now have experience with the use of our DNA and can provide examples of the type of genetic projects approved for use of the NHANES DNA samples, we hope we can continue to improve our consent 
rates and address any concerns that participants might have about the use of their biologic samples. ${ }^{10}$ Our experience between the 1999 to 2000 and 2001 to 2002 survey years demonstrates that interviewer training with specific information that addresses the participants' questions and concerns can significantly improve consent rates.

\section{ACKNOWLEDGMENTS}

U.S. government funds were used to support the operation of the survey and these analyses.

\section{References}

1. McQuillan GM, Porter KS, Agelli M, Kington RS. Consent for genetic research in a general population: The NHANES experience. Genet Med 2003;5(1):35-42.

2. National Center for Health Statistics. Plan and operation of the third National Health and Nutrition Examination Survey, 1988-94. Vital Health Stat 1. Hyattsville, MD: National Center for Health Statistics: 1994: No. 32.

3. National Center for Health Statistics. NHANES 19992004. http://www.cdc.gov/ nchs/about/major/nhanes/nhanes. Accessed 23 February 2006.

4. Bland JM, Altman DG. Multiple significance tests: the Bonferroni method. BMJ 1995;310:170.

5. Wang SS, Fridinger F, Sheedy KM, Khoury MJ. Public Attitudes regarding the donation and storage of blood specimens for genetic research. Community Genet 2001; $4: 18-26$.

6. Chen DT, Rosenstein DL, Palaniappan M, Hilsenbeck SG et al. Research with stored biologic samples: what do research participants want? Arch Intern Med 2005;165: 652-655.

7. Malone T, Catalano PJ, O'Dwyer PJ, Giantonio B. High rate of consent to bank biologic samples for future research: The Eastern Cooperative Oncology Group experience. J Natl Cancer Inst 2002;94:769-771.

8. Matsui K, Kita Y, Ueshima H. Informed consent, participation in, and withdrawal from population based cohort study involving genetic analysis. J Med Ethics 2005; 31:385-392.

9. Wendler D, Emanuel E. The debate over research on stored biologic samples: what do sources think? Arch Intern Med 2002;162:1457-1462.

10. Federal Register. Thursday, August 8, 2002 [67FR 51585-51589]

\section{APPENDIX 1}

\section{Future Research Q \& A's}

\section{What type of genetic research will be conducted using my DNA sample?}

Only research that tries to learn more about the health and nutrition of people living in the United States. Conditions likely to be looked at are those we ask questions about during the interview.

\section{How can I be sure this is the only research that will be conducted?}

All research studies have to be approved by a group of people who represent you called a review board. They are members of the community and outside scientists who are not involved in the survey. They oversee all research studies to ensure that only safe health research is conducted.

\section{Will my DNA be shared with law enforcement or other Federal agencies not doing health research?}

No! All health information and blood samples collected during the survey are kept strictly private. Under penalty of Federal law (section 308(d) of the Public Health Service Act [42 USC 242m] and the Privacy Act of 1974 [5 USC 552A]) we cannot give out your name, or any other information that could identify you.

If you agree to future research and the project is approved by the review board, no personal identifying information will be linked to the samples that the researchers use.

Samples will NEVER be shared with any agency or person who is not doing health research.

\section{Can you use my DNA sample for cloning?}

No! The samples we collect cannot be used for cloning.

\section{Why should I agree to future research?}

Many important scientific discoveries have been made using samples from previous NHANES surveys.

Samples from the NHANES conducted in the late 1970s showed that some Americans were more likely to be infected with the hepatitis B virus. This discovery resulted in a universal immunization program that began in 1991.

Stored samples have also been used to discover differences in nutrition, communities that might not have adequate childhood vaccinations, what causes tooth decay, and indicators of exposures to toxins in the environment. This information helps Congress identify problems that need national support to meet health objectives.

Without stored samples from you and your fellow survey participants, we will not be able to continue to look at the health of the nation as new scientific discoveries are made.

\section{What have stored blood samples from NHANES been used for in the past?}

You and other people who participate in the survey represent all Americans. When we test your blood we are able to see what the general health of the population looks like. In the past we have measured:

- how many people had been vaccinated with the measles vaccine

- how many people had been exposed to the hepatitis viruses

- how many people had sufficient vitamin levels from their diet

- how many people had been exposed to pesticides

- how many people were allergic to latex

The Centers for Disease Control use specimens that come from general surveys such as NHANES to compare communities that have an outbreak of an infection with the general population. Your samples become a control group representing the general population that is compared with samples from infected communities. This comparison helps identify the cause of an outbreak. In the past, stored NHANES samples have helped identify the cause(s) of:

- Hantavirus*

- Legionnaire's disease*

- Toxic shock syndrome* 
- Human immunodeficiency virus/acquired immune deficiency syndrome

- Lyme disease*

${ }^{\star}$ Hantavirus: Hantaviruses are carried by numerous rodent species throughout the world. In 1993, a previously unknown group of hantaviruses emerged in the United States and caused an acute respiratory disease now called hantavirus pulmonary syndrome.

${ }^{*}$ Legionnaire's disease: An acute illness, commonly characterized by fever, cough, and pneumonia. In the early 1980s, this disease was described and identified by the Centers for Disease Control when a group of Legionnaires attending a convention in a Philadelphia hotel developed pneumonia with a high fatality rate.
${ }^{*}$ Toxic shock syndrome: This was identified in the 1980 s when a new super-absorbent tampon came on the market. Women using this product developed staph infections. Some died of shock.

${ }^{\star}$ Lyme disease: Increased deer populations and suburban migration have exposed people to deer ticks that carry this newly described disease. Lyme disease was first recognized in the United States in 1975, after a mysterious outbreak of arthritis near Lyme, Connecticut. Since then, reports of Lyme disease have increased dramatically, and the disease has become an important public health problem in some areas of the United States. Symptoms include fever, chills, rash, and arthritis. 